\title{
PENGEMBANGAN BAHAN PEMBELAJARAN BLENDED LEARNING DALAM MATA KULIAH
}

\author{
${ }^{1}$ Irawan Suprapto, ${ }^{2}$ Dewi Sri Kuning \\ ${ }^{1}$ supratoirawan@gmail.com
}

\section{Universitas Muhammadiyah Kotabumi}

\begin{abstract}
Abstrack:Learning needs to be designed based on a need assessment and the need to develop learning materials that can answer learning problems in higher education. The development of Blended Learning materials is carried out to provide learning that can accommodate the breadth of required discussion and to elaborate on students' understanding, practice, and attitudes as competencies that are expected to be achieved in course learning. This paper aims to provide information about designing and producing blended learning materials that can solve learning problems. Dick and Carey's system approach model and Allan Jolliffe's webbased materials development model were used in the development of blended learning materials. The combination of learning materials, both printed and non-printed materials, can be arranged in face-to-face or non-face-to-face learning. Learning makes student activities and learning outcomes that make maximum learning outcomes. This paper describes the development of blended learning materials in higher education.
\end{abstract}

Keywords: Development, learning materials, blended learning

Abstrak: Pembelajaran perlu dirancang dengan mendasarkan need assessment dan perlunya pengembangan bahan pembelajaran yang dapat menjawab masalah pembelajaran di perguruan tinggi. Pengembangan bahan pembelajaran BlendedLearning dilakukan untuk memberikan pembelajaran yang dapat mengakomodasi luasnya bahasan yang diperlukan dan mengelaborasi pemahaman, praktik, dan sikap mahasiswa sebagai kompetensi yang diharapkan dicapai dalam pembelajaran mata kuliah. Tulisan ini bertujuan untuk memberikan informasi tentang merancang dan menghasilkan bahan pembelajaran blended learning yang dapat memecahkan masalah pembelajaran. Model pendekatan sistem Dick dan Carey dan model pengembangan bahan berbasis web oleh Allan Jolliffe digunakan dalam pengembangan bahan pembelajaran blended learning. Kombinasi bahan pembelajaran baik bahan cetak atau noncetak dapat diatur dalam pembelajaran tatap muka ataupun nontatap muka. Pembelajaran menjadikan aktivitas mahasiswa dan hasil pembelajaran yang menjadikan capaian pembelajaran maksimal. Tulisan ini menjelaskan pengembangan bahan pembelajaran blended learning di perguruan tinggi.

Kata kunci: Pengembangan, bahan pembelajaran, blended learning

\section{Pendahuluan}

Perkembangan pesat teknologi informasi dan komunikasi mendorong terjadinya proses globalisasi, dan seluruh bidang kehidupan tidak bisa dipisahkannya, termasuk sistem pendi-dikan. Menurut Khvilon (2002) sistem pendidikan diseluruh dunia kini di bawah tekanan yang

${ }^{1) 2}$ Dosen Universitas Muhammadiyah Kotabumi 
berkembang untuk menggunakan

Teknologi Informasi dan

Komunikasi dalam melaksanakan pembelajaran terhadap peserta didik tentang pengetahuan, keterampilan, dan sikap yang mereka butuhkan dalam abad ke-21. Sistem manajemen pembelajaran yang dirancang menggunakan unsur teknologi informasi dan komunikasi memungkinkan pengembangan pembelajaran secara elektronik (e-learning). Perlu upaya dan klarifikasi yang lebih besar agar kejelasan dan kemudahan penggunaan sistem manajemen pembelajaran dapat dirasakan peserta didik.

Deskripsi Kerangka Kualifikasi Nasional Indonesia yang dirumuskan dalam capaian pembelajaran memiliki 4 parameter deskripsi (1) sikap dan tata-nilai (deskripsi umum), (2) kemampuan di bidang kerja, (3) pengetahuan yang dikuasai, (4) hak/wewenang dan tanggung jawab. Tugas akademik mahasiswa dapat dikaitkan dengan tugas pembuatan makalah, paper, artikel, karya tulis ilmiah, laporan. Mahasiswa dalam kehidupan sehari-hari sering dijumpai bermedia sosial untuk hiburan dan mencari informasi di antaranya Face Book (FB), WahtsApp (WA), Instagram, Tik Tok, Snack Video, You Tube, Telegram, dan Tweetter. Bahasa yang digunakan dalam jejaring sosial cenderung untuk mengekspresikan diri yang terkadang kurang disadari kalau bahasa yang dipublikasi kurang layak. Masalah sosial bisa muncul ketika bentuk komunikasi sosial kurang didasarkan etika bermedia sosial sehingga bisa menjadi sarana saling menghujat, yang menyulut pada konflik yang bisa berakhir di ranah hukum. Dosen pengampu perlu melakukan perancangan pembelajaran yang dalam kurun waktu tertentu perlu melihat kembali apakah tujuan pembelajaran perlu disesuaikan dengan perkembangan yang sesuai. Tujuan pembelajaran dan silabus pembelajaran yang ada perlu dikembangkan secara maksimal sesuai kebutuhan mahasiswa.

Selama ini model pembelajaran yang dilaksanakan belum memadukan pembelajaran tatap muka dengan nontatap muka (baik secara synchronous dan asynchronous) secara blended learning dalam mengatasi masalah pembelajaran, terutama dalam mengatasi pemahaman materi praktik, etika penggunaan TIK maupun keterbatasan waktu pembelajaran. Krasnova dan Demeshko (2015)menyampaikan bahwa proses pendidikan berdasarkan blended learning optimal untuk transfer pengetahuan dan berkontribusi pada peningkatan kualitas pelatihan mahasiswa. Menurut Buran dan Evseeva (2015)menyatakan bahwa pembelajaran campuran memberikan sejumlah manfaat penting bagi dosen dan mahasiswa, menjadikan mereka peserta 
aktif dari proses pembelajaran yangbertanggung jawab atas hasil kerja mereka sendiri. Sedangkan Tosun (2015) menyampaikan bahwa belajar campuran, ketika dilaksanakan dengan baik, memiliki potensi untuk mendukung proses pembelajaran kosakata karena meningkatkan jumlah pembelajaran dibandingkan dengan pembelajaran di kelas. Hasil penelitian Rixt (2011) menyatakan bahwa penggunaan dan jenis latihan yang dipilih adalah penting jika Blended Learning untuk berkontribusi secara konstruktif terhadap pengalaman belajar, pilihan teknologi harus dimasukkan sehingga kekuatan lingkungan online dan offline dimanfaatkan secara optimal.

BlendedLearning berkontribusi secara konstruktif terhadap pengalaman belajar. Dari permasalahan di atas maka perlu dirancang pengembangan bahan pembelajaran Blended Learning. Bagaimanakah bahan pembelajaran blended learning dikembangkan?

\section{Model Pembelajaran Blended Learning}

Pengertian model menurut Smaldino, Lowther, dan Russell (2008) diartikan sebagai bentuk yang memiliki tiga ukuran (tiga dimensi) yang mewakili benda yang sebenarnya, bisa lebih kecil, sama, atau lebih besar untuk tujuan pembelajaran. Namun, pengertian model menurut Pribadi (2009) dapat bermakna sesuatu yang menggambarkan adanya pola berpikir, keseluruhan konsep yang saling berkaitan, sebagai upaya mengkonkritkan sebuah teori, juga representasi dari variabelvariabel yang terdapat dalam teori tersebut. Menurut Joyce, Weil, dan Calhoun (2009)menyatakan bahwa model pengajaran sesungguhnya model belajar. Istilah pengajaran (teaching) kini banyak ditinggalkan karena mengedepankan peran pengajar (teacher) yang dipersepsikan berpusat pada pengajar (teacher-centered or teacher oriented) dan digantikan dengan pembelajaran yang berpusat pada peserta didik (learner). Menurut Delors et al. (1998)bahwa pendidikan dalam kehidupan didasarkan 4 pilar sebagai fondasi pembaruan dan reformasi pendidikan: learning to know, learning to do, learning to live togather, and learning to be. Bangsa Indonesia sesuai dengan kondisi sosial kultural secara ekplisit termuat dalam UUD 1945 sebagai bangsa religius (berKetuhanan). Keempat pilar di atas berarti dilengkapi dengan satu pilar lagi yang lebih mendasar "learning to believe and to convince the almighty God".

Tujuan pendidikan tinggi di Indonesia adalah berkembangnya potensi mahasiswa agar menjadi manusia yang beriman dan bertakwa kepada Tuhan Yang Maha Esa dan berakhlak mulia, sehat, berilmu, cakap, kreatif, mandiri, terampil, kompeten, dan berbudaya untuk 
kepentingan bangsa (2012-LNRINomor158, 2012). Belajar untuk tahu, belajar untuk melakukan, belajar untuk hidup bersama, belajar untuk menjadi, serta belajar untuk percaya dan yakin sebagai mahluk Tuhan diharapkan menjadikan peserta didik sebagai pribadi yang cerdas dan berkarakter.

Menurut Smaldino et. Al. (2008) bahwa belajar merupakan sebuah istilah umum bagi perubahan yang relatif lama dalam kemampuan yang disebabkan oleh pengalaman, juga proses yang dengannya perubahan tersebut dihasilkan. Dari pengertian diatas dapat disimpulkan bahwa belajar adalah proses perubahan yang relatif menetap baik pengetahuan, keterampilan, sikap yang berkarakter dari pengalaman melalui indera seseorang. Pembelajaran adalah proses interaksi peserta didik dengan pendidik dan sumber belajar pada suatu lingkungan belajar (LNRI-NO 78, 2003). Sedangkan menurut Miarso (2009)pembelajaran adalah suatu usaha yang disengaja, bertujuan, dan terkendali agar orang lain belajar atau terjadi perubahan yang relatif menetap pada diri orang lain. Dari pengertian di atas dapat disimpulkan bahwa model pengembangan pembelajaran adalah ben-tuk sederhana yang mewakili sesuatu sistem yang kompleks berupa proses yang sistematis mencapai tujuan pembelajaran yang efektif dan efisien melalui pengidentifikasian masalah, pengembangan strategi dan bahan pembelajaran, serta melakukan revisi penyempurnaan rancangan pembelajaran setelah pengevaluasian.

Menurut Khan(2005) blended learning menggabungkan beberapa media penyampaian yang dirancang untuk saling melengkapidan meningkatkan belajarserta penerapan belajar perilaku. Pemahaman Khan bahwa belajar pada setiap siswa cenderung berbeda satu dengan yang lainnya. Maka pendekatan belajar yang bervariasi dalam strategi dan pengembangan bahan pembelajaran sangat perlu untuk memberikan kesempatan belajar yang lebih baik.

Menurut Graham (2006) blended learning system menggabungkan pembelajaran tatap muka dengan pembelajaran media komputer. Ide bahwa kombinasi pembelajaran menurut sejarah dari dua model terpisah, sistem belajar tatap muka tradisional dan sistem belajar menyebar, yang juga menekankan peranan sentral teknologi berbasis komputer dalam blended learning. Menurut Kim (2007) blended learning dapat didefinisikan sebagai kombinasi belajar di ruang kelas dengan e-learning. Istilah ini oleh Wong digunakan untuk e-learning secara longgar dalam memaknai belajar di luar ruang kelas tradisional menggunakan teknologi informasi untuk menyampaikan bahanbahan belajar. Menurut Dziuban (2008) 
lingkungan blended learning (blended learning environments) menggabungkan pembelajaran tatap muka dengan pembelajaran media teknologi. Istilah blended dan hybrid dapat digunakan secara bergantian. Menurut Thorne (2003) blended learning adalah campuran teknologi multimedia, CD ROM, video streaming, ruang kelas virtual, pesan suara, email dan panggilan konferensi, animasi teks online dan video streaming. Lebih lanjut menurut (Hadjerrouit, 2008)blended learning merupakan kombinasi e-learning dengan belajar tatapmuka. E-learning yang dimaksud pembelajaran berbasiskan mediasi komputer (computer based learning) dan online learning yang meliputi internet-based learning dan web-based learning. Online learning dan web based learning merupakan proses kegiatan yang memerlukan akses internet atau media berjaringan yang ketika digunakan peserta didik dapat dilakukan secara mandiri.

\section{Perkembangan} teknologi memungkinkan belajar secara bersamaan waktu (synchronous learning) yang dilakukan dalam belajar tatapmuka sekarang memungkinkan dilakukan dengan e-learning sebagaimana yang dikemukakan Singh (2006) secara praktis perkembangan blended learning, kelas virtual yang ditambahkan ke dalam campuran meliputi komunikasi dan kerjasama antara instruktur dan peserta didik dalam kapasitas langsung.
Menurut Dabbagh, N., dan BannanRithland (2005) bahwa online learning adalah lingkungan belajar terbuka dan terdistribusi yang menggunakan peralatan secara pedagogis, memungkinkan dengan internet dan teknologi berbasis web untuk memfasilitasi belajar dan membangun pengetahuan melalui kegiatan dan interaksi yang bermakna. . Online learning dapat disimpulkan merupakan belajar berbasis internet meliputi penympaian isi dalam berbagai format, pengelolaan pengalaman dan pengembangan isi belajar secara berjaringan.E-learning selain bisa digunakan secara online juga bisa offline, artinya dapat dilakukan melalui media komputer dengan tidak terhubungan internet, misalnya menggunakan $\mathrm{CD}$ pembelajaran.

Ada beberapa alasan bahwa seorang instruktur, trainer, atau peserta didik dapat memilih blended learning di antara pilihan belajar yang lainnya. Osguthorpe dan Graham mengidentifikasi enam alasan yang mungkin orang memilih untuk merancang atau menggunakan sistem Blended Learning: (1) pedagogical richness, (2) acces to knowledge, (3) social interaction, (4) personal agency, (5) cost-effectiveness, and (6) ease of revision (Graham, 2006). Metode penilaian yang digunakan dalam komponen ini akan bervariasi bergantung pada kebutuhan peserta didik dan topik yang diteliti tetapi pada dasarnya menurut 
(Jolliffe, A., Ritter, J., Stevens, 2012) ada tiga macam penilaia kuis online, tugas tertulis untuk meleng-kapi secara offline, dan ujian. Dalam model pembelajaran blended learning yang dilaksanakan untuk mata kuliah TIK diarahkan pada model pembelajaran tatap-muka yang dikombinasikan dengan pembelajaran nontatap-muka online.

\section{Bahan Pembelajaran Blended Learning}

Bahan pembelajaran campuran yang disampaikan secara tatap muka dikombinasikan secara online. Bahan belajar mandiri biasa disebut modul.

Pengertian modul pembelajaran menurut Smaldino (2012) merupakan suatu unit pembelajaran mandiri yang dirancang untuk digunakan peserta didik sendiri atau kelompok kecil tanpa kehadiran guru. Unit pembelajaran mandiri merupakan bahan pembelajaran yang dirancang sedemikian rupa sehingga mengarahkan mahasiswa secara komu-nikatif belajar secara mandiri, tanpa kehadiran guru mereka belajar mandiri. Menurut Dick et al. (2009) modul merupakan sebuah paket pembelajaran dengan satu tema terintegrasi dipantau berbagai pihak yang menyediakan informasi yang dibutuhkan untuk mengembangkan penguasaan pengetahuan, keterampilan, dan layanan sebagai satu komponen dari mata pelajaran atau kurikulum. Modul dapat digunakan untuk memberikan layanan pembelajaran pada satu mata pelajaran atau kurikulum.Pembelajaran yang fleksibel terdapat pada sistem belajar mandiri, menurut (Miarso, 2007) konsep dasar sistem belajar mandiri adalah pengaturan program belajar yang diorganisasikan sedemikian rupa sehingga tiap peserta didik/pelajar dapat memilih dan atau menentukan bahan dan kemajuan belajar sendiri. Menurut Suparman, modul pembelajaran adalah satu set bahan pembelajaran dalam kemasan terkecil dilihat dari lingkup isi, namun mengandung semua unsur dalam sistem pembelajaran sehingga bisa dipelajari secara terpisah dari modul yang lain (Suparman, 2014a). Dalam satu modul terdapat tiga komponen (1) bahan belajar (learning materials), (2) panduan belajar (study guide), (3) petunjuk pengajar atau tutor (teacher or manual tutor). Dalam sistem pendidikan jarak jauh, komponen pertama dan kedua dapat diintegrasikan menjadi satu, sedangkan petunjuk tutor terpisah dan khusus diperuntukkan bagi tutor, baik tutor tatap muka ataupun tutor online. Perbedaan utama sebuah modul dengan buku lain adalah bahwa semua prosedur pengaturan pembelajaran disediakan dalam modul.

Sistem pembelajaran kombinasi adalah gabungan kegiatan pembelajaran mandiri dengan tatap muka. Kegiatan 
pembelajaran campuran dalam mata kuliah seperti itu biasa disebut hybrit learning atau blended learning(Suparman, 2014b).Pendekatan sistem pembelajaran dengan sistem pembelajaran mandiri, bentuk bahan pembelajarannya berupa modul pembelajaran seperti yang digunakan dalam pendidikan jarak jauh. Menurut Lombardi (2007)nilai aktivitas otentik tidak dibatasi untuk belajar di lokasi yang nyata dan praktek, tetapi manfaat dari kegiatan otentik dapat diwujudkan melalui desain yang cermat lingkungan belajar berbasis Web. Jadi bahan pembelajaran blended learning dapat diwujudkan dalam bahan pembelajaran cetak dikombinasikan dengan bahan onlinee-learning dalam web pembelajaran.Ketertarikan dalam menciptakan pengalaman belajar yang lebih efektif, meningkatkan akses dan fleksibilitas, atau mengurangi biaya belajar, ada kemungkinan bahwa sistem pem-belajaran akan memberikan campuran dari tatapmuka dan pengalaman mediasi komputer. Sistem belajar di masa men-datang dibedakan tidak berdasarkan apakah mereka berbaur melainkan dengan bagaimana mereka berbaur. Pertanyaan tentang bagaimana untuk berbaur tatap muka dan pembelajaran mediasi komputer yang efektif adalah salah satu yang paling penting dipertimbangkan.

Pembelajaran blended learning merupakan campuran pembelajaran tatap muka dengan online learning. Online learning juga disebut electronic learning atau e-learning menurut Smaldino (2012) online learning merupakan hasil dari pembelajaran yang disampaikan secara electronik menggunakan media berbasis komputer. Materinya sering diakses melalui jaringan, termasuk situs web, internet, intranet, CD, DVD. Keuntungan E-learning menurut Smaldino (2012) adalah (1) variety of media, (2) up-to-date information, (3) navigation, (4) idea exchange, (5) convenient communication, (6) low cost.

Keterbatasan elearning menurut Smaldino (2012) adalah (1) inappropriate material, (2) copyright, (3) finding information, (4) support, (5) access, (6) access speed. (7) lack of quality control. Kelemahan lingkungan tatapmuka (diskusi dalam kelas): Peranserta (participation): Tidak semua orang dapat selalu memiliki peranserta, terutama jika ada kepribadian mendominasi. Keluwesan (Flexibility): terbatas waktu, yang berarti bahwa persertadidik mungkin tidak dapat mencapai kedalaman diskusi yang 
diinginkan. Komponen blended learning menurut Said Hadjerrouit dapat dilihat pada gambar 10 berikut ini.

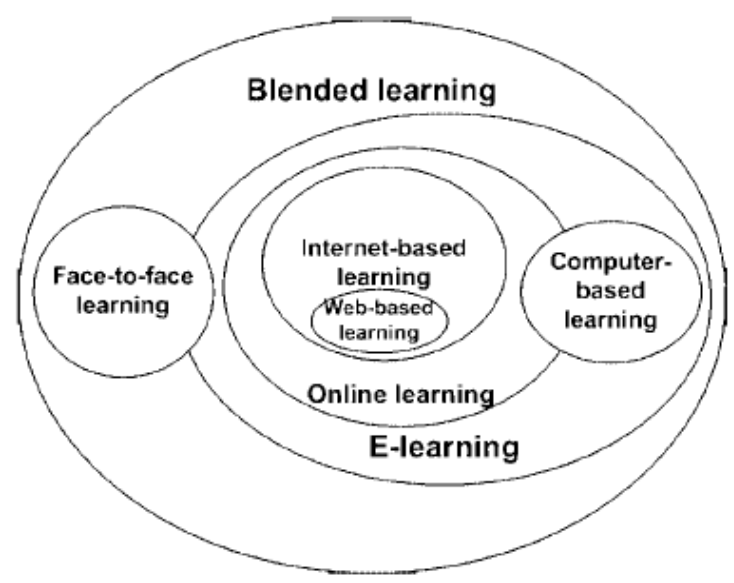

Gambar 1. Components of Blended Learning (Hadjerrouit, 2008)

Komponen blended learning secara garis besar meliputi belajar tatapmuka (face-to-fasce learning) dan belajar berbasiskan komputer (computer-based learning) e-learning. E-learning bisa dilaksanakan dalam melengkapi pembelajaran tatapmuka dengan belajar berbasiskan komputer (computer-based learning).

Online learning dan offline learning merupakan bagian dari e-learning. Offline learning bisa merupakan computer-based learning yang digunakan tanpa koneksi internet. Online learning bisa merupakan computer-based learning yang secara khusus dapat memunculkan belajar bebasiskan internet (internet-based learning), dan lebih khusus dapat dirancang belajar berbasiskan web (web-based learning).

.Menurut (Chapman, 2008) untuk merancang dan mengembangkan bahan maka pembelajaran dapat terjadi dengan komunikasi antara peserta didik dengan dosen tidak meletakkan tempat secara bersamaan atau waktu yang digunakan. Perkembangan ilmu pengetahuan dan teknologi khususnya teknologi informasi dan komunikasi memungkinkan bahan pembelajaran yang dikembangkan dengan pendekatan blended learning, pada pelaksanaannya dapat disesuaikan sebagaimana menurut (Allen, A., Seaman, 2011)pembelajaran blended (kadangkadang disebut hybrid) memiliki antara 30 sampai 80 persen isi kursus disampaikan secara online. Dalam strategi pembelajaran akan ditetapkan tujuan pembelajaran umum yang didukung tujuan pembelajaran khusus. Masing-masing tujuan pembelajaran khusus memiliki sub tujuan pembelajaran khusus atau indikator tujuan pembelajaran khusus.

\section{Pengembangan Bahan Pembelajaran Blended Learning}

Model desain pengembangan digunakan untuk menciptakan program pembelajaran yang efektif dan efisien serta menarik yang dikembangkan didasarkan penggunaan pendekatan sistem. Model pengembangan bahan pembelajaran 
blended learning didasarkan model desain

Dick dan Carey yang komponennya sebagai langkah utama model desain sistem pembelajaran yang meliputi sebagai berikut.

Components of the systems approach model: 1) identify instructional goal(s), 2) conduct instructional analysis, 3) analyze learners and contexts, 4) write performance objectives, 5) develop assessment instrument, 6) develop instructional strategy, 7) develop and select instructional materials, 8) design and conduct formative evaluation of instruction, 9) revise instruction, 10) design and conduct summative evaluation (2005:6).

Model pendekatan sistem dalam merancang pembelajaran Dick dan Carey dapat dilihat pada gambar berikut.

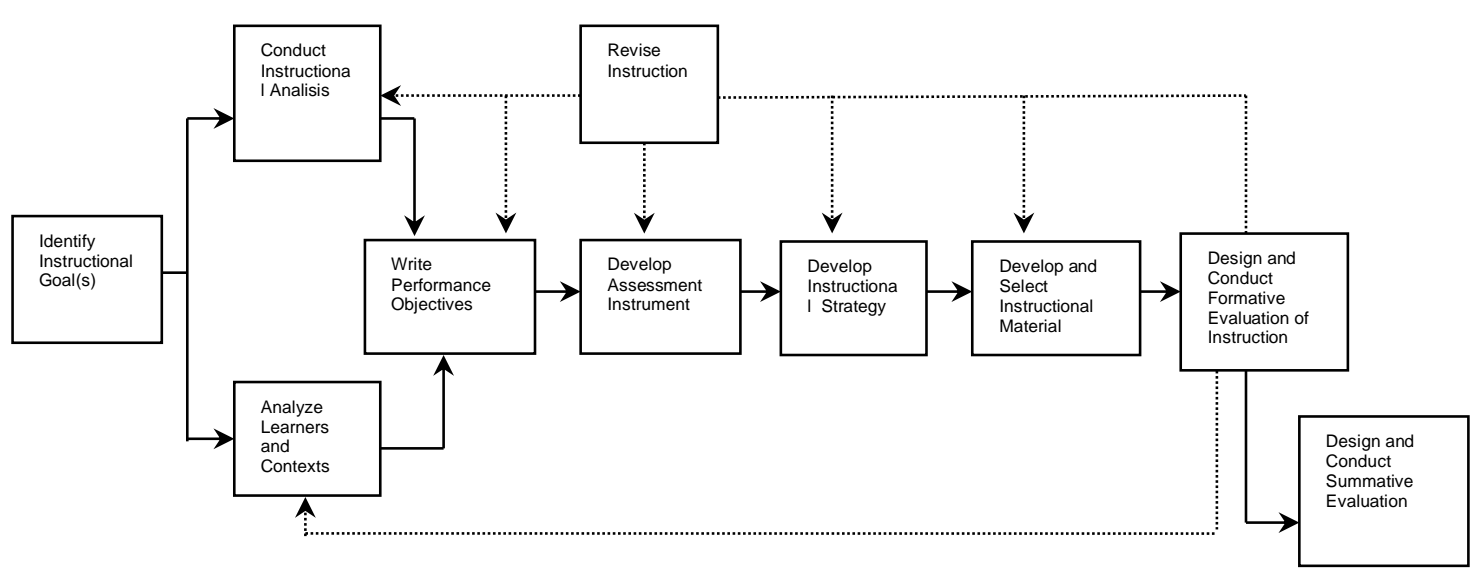

Gambar 2 The Dick and Carey Systems Approach Model of Designing Instruction (Dick, Wolter; Carey, Lou ; Carey, 2005: 1).

Pengembangan bahan pembelajaran blended learning merupakan dasar-dasar rancangan konsep-konsep dan prosedur untuk penganalisisan, peran-cangan, pengembangan, pengevaluasian bahan pembelajaran secara formatif. Sembilan langkah dasar merupakan serangkaian prosedur yang menggunakan pendekatan sistem untuk merancang suatu pembelajaran. Dalam penelitian ini dipilih "The Systematic Design of Instructional" oleh Dick dan Carey, karena pertimbangan sebagai berikut (1) model Dick dan Carey berdasarkan prinsip belajar dan pembelajaran yang dapat digunakan secara kombinatif baik untuk pembelajaran tatap muka maupun pendidikan jarak jauh yang relevan dengan pengembangan bahan pembelajaran blended learning mata kuliah. (2) model tersebut dapat digunakan untuk merancang skala kecil seperti mata kuliah (mata pelajaran, kursus dan sesi) 
yang menjadi tanggung jawab dosen. (3) keahlian mendesain pembelajaran diperlukan oleh dosen yang bermaksud mengembangkan sistem pembelajaran secara sistematik, efektif, dan efisien.

Filosofi pendidikan mutakhir, pandangan konstruktivisme menganggap bahwa semua peserta didik dari usia dini sampai dengan perguruan tinggi memiliki gagasan/ pengetahuan tentang lingkungan dan peristiwa/gejala lingkungan sekitarnya. Sekolah mengajarkan pema-haman, pengetahuan, dan kearifan (Meier, 2003). Menurut (Suparno, 2005) sebagai fasilitator menyediakan sumber belajar atau mengidentifikasi sumber belajar yang dapat diekplorasi mahasiswa, memberi tugas yang menantang, menunjukkan kedisplinan, kegigihan, dan ketertarikan dalam memperdalam suatu konsep. Teknologi Informasi sebagai alat bantu interaksi pembelajaran memerlukan perancangan pembelajaran yang sistematik. Sejak awal perlu kejelasan keterampilan atau kompetensi yang akan dicapai, kemudian mempertimbangkan dampak pengiring dan nilai tambah, jangka waktu interaksi dan cara interaksi dilakukan. Para futurolog, Peter Drucker, John Naisbitt, Kenichi Ohmae, Robert Reich, semua mengakui adanya kecenderungan baru: pergeseran dari masyarakat industri ke service society (Vos, 2003). Berarti dalam dunia pendidikan, khususnya model pembelajaran yang kaku dan tidak fleksibel akan bergeser sesuai dengan kemajuan zaman, yaitu pembelajaran yang fleksibel dan menyenangkan. Belajar akan efektif bila dalam keadaan menyenangkan. Pengembangan bahan pembelajaran blended learning mata kuliah mesti memadukan bahan pembelajaran cetak untuk pembelajaran secara konvensional tatap muka di kelas dengan bahan pembelajaran online/ e-learning.

Model pengembangan bahan pembelajaran blended learning mengadaptasi dari model pendekatan sistem Dick dan Carey. Rancangan model pengembangan bahan pembelajaran blended learning mata kuliah terdiri dari 9 langkah yang keseluruhan langkah tersebut merupakan sistem pembelajaran blended learning. Model pengembangan bahan pembelajaran blended learning mata kuliah berbasis model Dick dan Carey dapat dilihat pada gambar model berikut. 


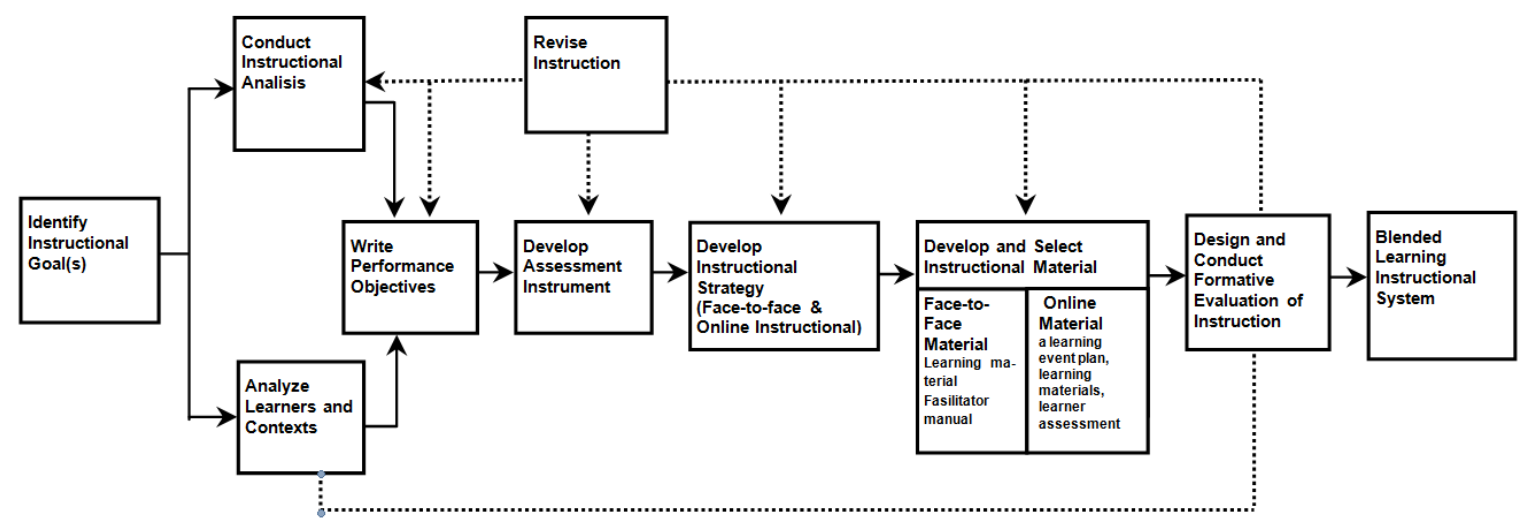

Gambar 3 Model Pengembangan Bahan Blended Learning Mata Kuliah

Model pengembangan bahan pembelajaran blended learning tersebut dapat dijelaskan sebagai berikut. (1) Mengidentifikasi tujuan pembelajaran umum (identify instructional goal [s]). Mengidentifikasi tujuan pembelajaran umum diawali dengan mengenali kebutuhan pembelajaran.

Ada tiga sumber informasi dalam mengidentifikasi kebutuhan pembelajaran yakni peserta didik, masyarakat, dan pendidik. Informasi tentang kurangnya maksimal prestasi peserta didik yang disebabkan kurangnya pengetahuan, keterampilan, dan sikap dapat diatasi dengan kegiatan pembelajaran.

Tujuan pembelajaran dirumuskan sebelum peserta didik mulai belajar dan mesti berorientasi pada hasil belajar. Rumusan tujuan dalam kalimat dengan kata kerja yang operasional yang dapat diamati dan diukur. (2) Melaksanakan analisis pembelajaran (conduct instructional analysis). Tujuan pembelajaran umum sebagai kompetensi umum peserta didik yang telah teridentifikasi selanjutnya dapat dijabarkan menjadi sub kompetensi (kompetensi dasar) yang tersusun secara logis dan sistematik baik secara hirarkhis, prosedural, pengelompokan, atau kombinasi. Langkah ini dilaksanakan dengan mengidentifikasi keterampilan khusus, prosedur, belajar tugas-tugas yang dimasukkan dalam mencapai tujuan-tujuan pembelajaran.

Menentukan perilaku entri (entry behavior) yang merupakan kompetensi khusus yang mesti dikuasai sebelum memasuki aktivitas pembelajaran yang diberikan.

(3) Menganalisis peserta didik dan konteks (analyze learners and contexts). Selain menganalisis tujuan pembelajaran umum maka ada analisis paralel dari 
peserta didik dan konteks yang terkait dengan mereka yang akan belajar baik pengetahuan, keterampilan, minat, maupun sikap dan konteks yang akan mereka gunakan. Identifikasi tingkatan kemampuan keterampilan dan sikap awalpeserta didik, karakteristik susunan pembelajaran, dan pengaturan yang di dalamnya pengetahuan dan keterampilan yang akan digunakan. Pengetahuan karakteristik awal peserta didik diperlukan dalam menentukan strategi pembelajaran khususnya dalam menentukan metode, media, dan alat serta bantuan belajar. (4) Menuliskan tujuan pembelajaran khusus (write performance objectives). Penerjemahan kebutuhan dan tujuan pembelajaran umum atau tujuan pembelajaran umum ke dalam sub kompetensi atau tujuan kinerja atau tujuan pembelajaran khusus. Juga memberikan dasar perencanaan yang teliti dari instrumen pengukuran, strategi pembelajaran, dan bahan pembelajaran.

(5) Mengembangkan instrumen penilaian (develop assessment instrument). Instrumen-instrumen secara terarah dihubungkan dengan pengetahuan, keterampilan, sikap dalam tujuan pembelajaran khusus yang sudah ditulis. Keterampilan intelektual yang menghasilkan suatu produk atau kinerja, keterampilan psikomotor dan perilaku yang berhubungan dengan sikap harus diukur dengan menggunakan tes yang terdiri dari instruksi peserta didik dan instrumen observasi penilai (Dick, et al., 2005).

Perlu memilih format penilaian yang masuk akal dan menentukan bagaimana instrumen akan dinilai (diberi skor). Pengembangan penilaian mesti paralel dan mengukur kemampuan atau kompetensi peserta didik atau kinerja dari hasil belajar peserta didik. Ada tiga jenis tes yakni tes esai, tes objektif, dan tes kinerja. Tes obyektif pilihan ganda dengan tes acuan patokan yang diarahkan mengukur atau menilai kompetensi peserta didik. Tes kinerja berupa kombinasi daftar cek (checklist) yang dikombinasikan dengan skala nilai. Untuk mengukur tujuan pembelajaran khusus yang berupa sikap maka digunakan skala sikap.

(6) Mengembangkan strategi pembelajaran (develop instructional strategy). Pengembangan ini untuk membantu peserta didik dengan usahanya mencapai setiap tujuan pembelajaran secara tatap muka yang dikombinasikan secara nontatap muka (pembelajaran berbasis web). Menurut (Woodal, 2015) dalam solusi blended learning harus menempatkan sesuaipenekanan pada kedua domain pembelajaran yang penting. (1) Metode Pembelajaran Singkron (Synchronous Instructional Methods). Dalam strategi blended learning metode pembelajaran singkron terdiri dari: ruang kelas tradisional 
(traditional classroom), kelas virtual (virtual classrooms), live product practice $(l a b)$, interactive chat and mentoring (coaching). (2) Metode Pembelajaran Asingkron (Asynchronous Instructional Methods). Metode pembelajaran asingkron terdiri dari of documents and web pages, web-based training (WBT), computerbased training (CBT), CD-ROM, assessments, tests, surveys, simulations and labs and recorded live events. Penyusunan strategi pembelajaran harus didasarkan atas tujuan pembelajaran yang akan dicapai sebagai kriteria utama. Menurut (Allen, A. , Seaman, 2011) pembelajaran blended (kadang-kadang disebut hybrid) memiliki antara 30 sampai 80 persen isi kursus disampaikan secara online. Metode blended learning secara garis besar menggunakan metode singkronous (synchronous method) dan metode asingkronous (asynchronous method).

Model strategi pembelajaran tatap muka dan nontatap muka dirancang secara terpadu meliputi tiga tahap: pendahuluan, penyajian, dan penutup. Pendahuluan terdiri dari: penjelasan singkat isi pelajaran, penjelasan relevansi isi pelajaran, dan tujuan pembelajaran khusus. Penyajian meliputi: uraian, contoh - noncontoh, latihan, dilanjutkan tes formatif, rangkuman, glosarium. Penutup meliputi: umpan balik, dan tindak lanjut. Pembelajaran mata kuliah menggunakan pendekatan blended learning, proporsi pembelajaran tatap muka dan pembelajaran mandiri dengan web/ online berkisar $30 \%$ sampai dengan $80 \%$.

$$
\text { Pembelajaran tatap muka }
$$
(konvensional) digunakan secara efisien dan efektif untuk diskusi mendalam dan praktik di laboratorium, dan pembelajaran online/ offline digunakan untuk saling melengkapinya, bahkan dapat menggantikan pembelajaran konvensional tatap muka secara reguler. Beberapa tugas terstruktur dan mandiri dilaksanakan secara online (a) pembelajaran singkronous tatap muka: presentasi dosen, presentasi dan diskusi kelompok, praktik software, (b) pembelajaran singkronous maya: chatting reguler setiap kali dosen online, (c) pembelajaran asingkronous (i) asingkronous mandiri: memelajari elektronik materi ( $p d f, f l v, h t m l)$ secara mandiri, (ii) asingkronous kolaboratif: diskusi melalui forum diskusi, tugas terstruktur dan mandiri melalui tugas online. Tujuan pembelajaran didasarkan pada peta kompetensi.Rumusan tujuan pembelajaran umum didukung tujuan-tujuan pembelajaran khusus dengan indikatornya dicapai melalui pembelajaran tatap muka yang dikombinasikan dengan pembelajaran online. 
(7) Mengembangkan dan memilih bahan pembelajaran (develop and select instructional materials). Pendekatan sistem pembelajaran kombinasi bahan pembelajarannya adalah bahan pembelajaran kombinasi yang terdiri dari modul pembelajaran dan bahan pembelajaran online. Bahan pembelajaran kombinasi mengacu pada strategi pembelajaran. Pengembangan bahan pembelajaran digunakan pendekatan blended learning dengan menyiapkan bahan pembelajaran tatap muka di kelas dan bahan pembelajaran mandiri secara online. Menurut Suparman (2014a) panduan peserta didik meliputi tiga (1) cara penggunaan semua bahan instruksional, (2) daftar kegiatan yang harus dilakukan secara berurutan setiap unit pelajaran atau pertemuan, (3) petunjuk yang rinci tentang cara dan waktu yang tepat dalam menggunakan setiap set bahan instruksional. Untuk bahan instruksional campuran (blended learning), pedoman peserta didik sebaiknya dibuat tersendiri untuk menghindari kompleksitas.

Bahan pembelajaran ditulis dengan bahasa keilmuan yang ciri-cirinya sebagai media karya ilmiah diantaranya reproduktif, tidak ambigu, tidak emotif, penggunaan bahasa baku dalam ejaan, penggunaan istilah keilmuan, bersifat dekoratif, rasional, ada kohesi antar kalimat, bersifat langsung ke sasaran, penggunaaan kalimat efektif (Arum,
2015).Jolliffe, A., Ritter, J., Stevens (2012) dalam mengembangkan belajar berbasis web (web-based learning), terutama dalam mengembangkan bahan belajar mengembangkan model yang didasari Dick dan Carey sebagai berikut.

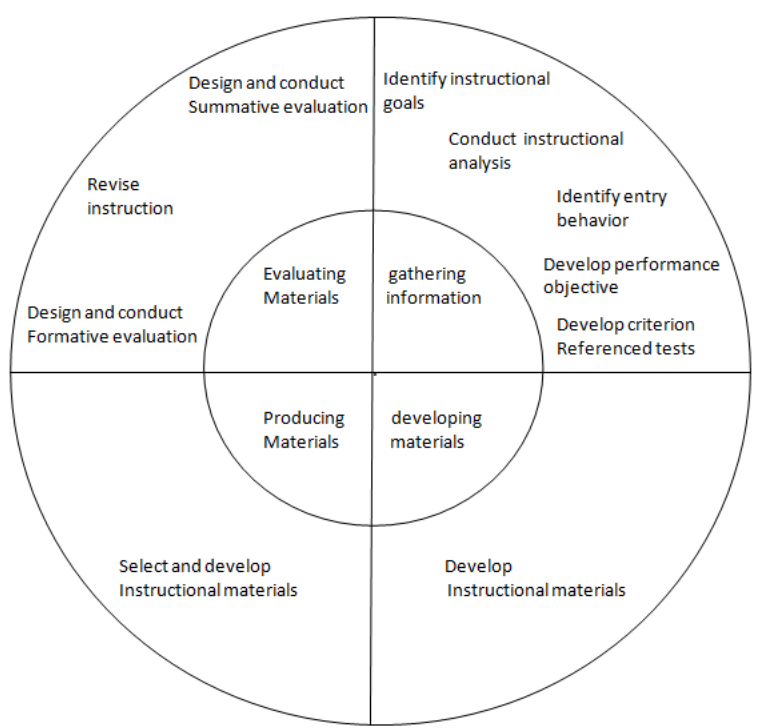

Gambar 4.A Model for The Development of Learning Materials (Jolliffe et al. , 2012:63)

\section{(8) Merancang dan melak-} sanakan evaluasi formatif (design and conduct formative evaluation of instruction). Idealnya, tahap evaluasi formatif dilakukan empat langkah (1) evaluasi satu-satu oleh pakar (one-to-one evaluation by experts). (2) evaluasi satusatu oleh peserta didik (one-to-one evaluation by learner). (3) evaluasi kelompok kecil (small group evaluation), oleh peserta didik dan pengajar. (4) uji coba lapangan (field tryout evaluation) oleh peserta didik dan pengajar. Setiap langkah 
diikuti dengan revisi (Suparman, 2014a). Uji coba lapangan memerhatikan penentuan sampel yang digunakan sekitar 30 orang peserta didik, penyiapan lingkungan, fasilitas, dan alat-alat yang dibutuhkan sesuai strategi dan bentuk kegiatan instruksional yang telah ditentukan, menyelenggarakan tes, melaksanakan kegiatan instruksional sesuai dengan bahan dan bentuk kegiatan instruksional, mengumpulkan data dan informasi.

\section{Merevisi}

produk pembelajaran (revise instruction). Rangkaian kegiatan dalam langkah merancang dan melaksanakan evaluasi formatif meliputi (a) penelaahan oleh pakar dan revisi; (b) Evaluasi oleh 1-3 peserta didik dan revisi; (c) Uji coba dalam skala terbatas yang melibatkan sekelom-pok kecil peserta didik, pengajar, dan sarana penunjang diikuti dengan revisi; (d) Uji coba lapangan seperti keadaan yang sebenarnya dengan melibatkan semua komponen dalam sistem sesungguhnya dan revisi. Revisi produk program pembelajaran yang dikembangkan berupa revisi draf bahan pembelajaran. Data hasil evaluasi formatif dirangkum dan ditafsirkan untuk mengetahui kelemahan draf program pembelajaran. juga evaluasi formatif perlu dilaksanakan pada semua aspek rancangan program seperti, analisis pembelajaran, entry behavior, dan karakteristik peserta didik, agar kualitas program pembelajaran yang dirancang meningkat. Menganalisis data dan merevisi produk pembelajaran berdasarkan evaluasi satu-satu oleh para ahli/pakar yaitu dengan cara menginterpretasikan hasil wawancara. Hasil data dan informasi dianalisis dan ditafsirkan menjadi rekomendasi untuk dasar revisi bahan pembelajaran.Produk pembelajaran dalam penelitian ini merupakan bahan pembelajaran blended learning yang ketika sebagai prototipe maka direvisi berdasarkan evaluasi formatif.

Yusoff, Yusoff, \& Md Noh (2017) mengemukakan bahwa blended learning dapat digunakan sebagai pendekatan pengajaran untuk siswa yang kurang mahir dalam kursus Pengantar Statistik. Namun, dimensi pembelajaran campuran harus disesuaikan agar sesuai dengan gaya belajar siswa. Pendekatan pembelajaran campuran memiliki banyak manfaat namun harus disesuaikan dengan tingkat kognitif siswa serta gaya belajaryang berbeda.

Siswa yang mahir rata-rata dapat dengan cepat membiasakan diri dan beradaptasi dengan pendekatan pembelajaran terpadu, kurang dari rata-rata siswa mahir perlu memiliki pemantauan tambahan untuk mendorong partisipasi yang lebih tinggi. Salah satu elemen penting dalam modul Redesigned Blended Learning adalah peningkatan kesempatan 
untuk interaksi sosial akademik di antara para siswa..

Pengembangan ilmu pengetahuan dan teknologi dan globalisasi memungkinkan pengembangan pembelajaran blended learning sebagaimana dikemukakan Aritonang (2014) bahwa campuran belajar tatap muka dan online tampaknya lebih efektif untuk kursus pengembangan guru di Indonesia. Desain pengembangan model pembelajaran dalam pendidikan mengisyaratkan adanya upaya perbaikan dan peningkatan kualitas pembelajaran dengan tujuan hasil belajar menjadi lebih baik.

\section{PENUTUP}

Pengembangan bahan pembelajaran blended learning mata kuliah akan dapat memecahkan masalah pembelajaran meliputi perbaikan tujuan pembelajaran dan silabus pembelajaran agar memenuhi kebutuhan belajar mahasiswa, lembaga dan stake holder (pemangku kepentingan). Strategi pembelajaran dikembangkan berdasarkan urutan kegiatan, metode dan media bahan berupa modul cetak dan bahan noncetak sesuai waktu yang disediakan, Bahan pembelajaran blended learning mata kuliah yang dirancang sebagai model fisikal bahan pembelajaran campuran bahan cetak dan bahan online. Pembelajaran tatap muka menggunakan modul pembelajaran cetak.
Pembelajaran online dapat digunakan media pembe-lajaran Zoom Metting yang dapat dikombinasikan dengan web blog, dan media sosial yang berkembang yang juga mendukung praktik terutama video pembelajaran dan materi pdf yang juga ada link yang dapat memperjelas pemahaman sesuai topik pembelajaran yang dirancang berdasarkan tujuan pembelajaran. Bahan pembelajaran berupa modul pembelajaran dan materi pembelajaran online diuji kelayakannya secara teoritis oleh beberapa pakar. Pengujian secara empiris dilakukan terhadap peserta didik melalui evaluasi formatif. Evaluasi formatif melalui evaluasi satu-satu peserta didik (one to one by leaners), evaluasi kelompok kecil (small group), maupun uji coba lapangan (field tryout atau field testing).

Bahan pembelajaran blended learning dapat digunakan oleh dosen pengampu mata kuliah. Penggunaan bahan pembelajaran blended learning yang telah dikembangkan, dapat meningkatkan proses pembelajaran karena menarik minat peserta didik, dan meningkatkan hasil belajar belajar. Beberapa rekomendasi yang dapat disampaika peneliti diantaranya adalah sebagai berikut.

1. Pembelajaran blended learning dapat dilaksanakan sekitar 30\% sampai dengan $70 \%$ artinya secara online dan tatap muka porsinya dapat disesuaikan 
dengan kebutuhan pembelajaran yang dirancang.

2. Keterbatasan pemilikan komputer dan paket internet (laptop, desktop/ computer pribadi, dan HP androit) bagi peserta didik dapat diatasi dengan fasilitas hotspot area dan laboratorium computer kampus.

\section{DAFTAR PUSTAKA}

2012-LNRI-Nomor158, K. (2012). Undang - Undang RI No 12 Tahun 2012 tentang Pendidikan Tinggi. https://doi.org/10.1073/pnas.0703993104

Allen, A. , Seaman, J. (2011). Going The Distance: Online Education in the United States. Diambil dari http://www.onlinelearningsurvay.com/reports/goingthedistance.pdf

Aritonang, M. (2014). Motivation and Confidence of Indonesian Teachers To Use English As a Medium of Instruction. TEFLIN Journal, 25(2), 147-167. https://doi.org/10.15639/TEFLINJOURNAL.V25I2/147-167

Arum, I. M. (2015). Konsep Dasar Menulis Karya Ilmiah.

Buran, A., \& Evseeva, A. (2015). Prospects of Blended Learning Implementation at Technical University. Procedia - Social and Behavioral Sciences, 206(November), 177182. https://doi.org/10.1016/j.sbspro.2015.10.049

Chapman, B. L. (2008). Tool for Design and Development of Online Instruction, Hand Book of Research on Educational Communications and Technology. New York: AECT.

Dabbagh, N., dan Bannan-Rithland, B. (2005). Online Learning : Concepts, Strategies and Application. New Jersey: Pearson Prentice Hall.

Delors, J., Chung, F., Gorham, W., \& Manley, M. (1998). Learning: The Treasure Within (Highlights), 45.

Dick, Wolter; Carey, Lou; Carey, J. O. (2005). The Systematic Design of Instruction (sixth). Boston: Pearson.

Dziuban, C. R. G. \& C. (2008). Blended Learning Environments”, in Spector,J.M., at all, Handbook of Research on Educational Communications and Technology, Third Edition. New York: Lawrence Erlbaum Associates.

Graham, C. R. (2006). Blanded Learning System: : Definition, Current Trends, and Future Directions" In Curtis J. Bonk \& Charles R. Graham, Handbook of blended learning: Global perspectives, local designs. San Francisco: Pfeiffee, A Wiley Imprint. https://doi.org/10.1093/ehr/V.XVII.117

Hadjerrouit, S. (2008). Towards a Blended Learning Model for Teaching and Learning 
Computer Programming: A Case Study. Informatics in Education, 7(2), 181-210.

Jolliffe, A., Ritter, J., Stevens, D. (2012). The Oline Learning Handbook, Developing and Using Web-Based Learning. London: Routledge.

Joyce, Bruce ; Weil, Marsha; Calhoun, E. (2009). Models of Teaching. Boston: Pearson.

Khan, B. (2005). Managing E-Learning Strategies: Design, Delivery, Implementation and Evaluation (Vol. 202). Hershey: Information Science Publishing.

Khvilon, E. (2002). Information and Communication Technologies in Teacher Education, A Planning Guide (Vol. 84). Paris. Diambil dari http://ir.obihiro.ac.jp/dspace/handle/10322/3933

Kim, W. (2007). Toward Definition and Methodology for Blended Learning", in Joseph Fong and Fu Lee Wang, Blended Learning. In Proceeding Workshop on Blended Learning 1517 August 2007 (hal. 2).

Krasnova, T., \& Demeshko, M. (2015). Tutor-mediated Support in Blended Learning. Procedia - Social and Behavioral Sciences, 166, 404-408. https://doi.org/10.1016/j.sbspro.2014.12.544

LNRI-NO78, U. S.-P.-N. (2003). Undang-undang Sistem Pendidikan Nasional.

Lombardi, M. M. (2007). Authentic Learning for The 21st Century: An Overview. Edited by Diana G. Obliger. Washington DC: The EDUCAUSE Learning Initiative (ELI.

Meier, D. (2003). The Accelerated Learning, Handbook: Panduan Kreatif \& Efektif Merancang Prog. Pendidikan dan Pelatihan, Terjemahan Rahmani Astuti. Bandung: Khaifa.

Miarso, Y. (2007). Menyemai Benih Teknologi Pendidikan. Computer. https://doi.org/10.1038/cddis.2011.1

Miarso, Y. (2009). Menyemai Benih Teknologi Pendidikan.pdf (4 ed.). Jakarta.

Pribadi, B. A. (2009). Model Desain Sistem Pembelajaran. Jakarta: PT Dian Rakyat.

Rix, R. W. (2011). Blended learning: Perspectives on mixing online and offline communities of enquiry. E-Learning and Digital Media, 8(4), 423-433.

https://doi.org/10.2304/elea.2011.8.4.423

Sharon E. Smaldino, D. L. L. J. D. S. (2012). Instructional Technology \& Media For Learning Teknologi Pembelajaran dan Media untuk Belajar. Penterjemah : Arif Rahman. (Kencana, Ed.). Jakarta.

Singh, H. (2006). Blended Learning and Work: Real-time Flow Learning”, in Curtis J. Bonk \& Charles R. Graham, Handbook of blended learning: Global perspectives, local designs. San Francisco: Pfeiffee, A Wiley Imprint. 
Smaldino, Sharon E. , Lowther, Deborah L., Russell, J. D. (2008). Instructional Technology and Media for Learning. New Jersey, Columbus, Ohio: Pearson.

Suparman, M. A. (2014). Desain Instruksional Modern: Panduan Para Pengajar dan Inovator Pendidikan (4 ed.). Jakarta: Erlangga.

Suparno, A. S. (2005). Peningkatan Kualitas Peningkatan Kualitas Pembelajaran, Depdiknas. Jakarta: Direktorat Pembinaan Pendidikan Tenaga Kependidikan dan Ketenagaan Perguruan Tinggi.

Thorne, K. (2003). Blended learning : How to Integrate Online and Traditional Learning. Great Britain and the United States: Kogan Page Limited.

Tosun, S. (2015). The Effects of Blended Learning on EFL Students' Vocabulary Enhancement. Procedia - Social and Behavioral Sciences, 199, 641-647. https://doi.org/10.1016/j.sbspro.2015.07.592

Vos, G. D. \& J. (2003). The Learning Revolution, Word + + Translation Service. Bandung: Kaifa.

Walter Dick, L. C. dan J. O. C. (2009). The Systematic Design of Instruction 7ed. Boston: pearson.

Woodal, D. (2015). Blended Learning Strategies: Selecting The Best Instructional Method.

Yusoff, S., Yusoff, R., \& Md Noh, N. H. (2017). Blended Learning Approach for Less Proficient Students. SAGE Open, 7(3), 1-8. https://doi.org/10.1177/2158244017723051 